\title{
AS HABILIDADES SOCIAIS DOS JOGADORES DE RPG
}

\author{
Social skills in RPG players
}

\author{
Dhayana Inthamossu Veiga ${ }^{a}$, Mariana Galesi Bueno ${ }^{\mathrm{b}}$, \\ Marcela Godinho Belém ${ }^{c}$, Andréia Schmidt ${ }^{\mathrm{d}}$
}

\footnotetext{
a Aluna do curso de Psicologia do Centro universitário Positivo, Curitiba, PR - Brasil, e-mail: dhayanaveiga@-hotmail.com

b Aluna do curso de Psicologia do Centro universitário Positivo, Curitiba, PR - Brasil, e-mail: mmaranag@hotmail.com c Aluna do curso de Psicologia do Centro universitário Positivo, Curitiba, PR - Brasil, e-mail: marcelgbrlem@hotmail.com

d Doutora em Psicologia Experimental e professora do curso de Psicologia do Centro Universitário Positivo - UnicenP, Curitiba, PR - Brasil, e-mail: andreia.schmidt@unicenp.edu.br.
}

\begin{abstract}
Resumo
O role playing game (RPG) é um jogo de representações verbais cujo número de adeptos cresce consideravelmente, apesar de receber críticas por supostamente estimular comportamentos nãoaceitos socialmente. Não há confirmação destes dados, mas há indícios de que os jogadores possam apresentar déficits de habilidades sociais. O objetivo desta pesquisa foi verificar se as habilidades sociais dos jogadores de RPG diferem das habilidades sociais da população não-jogadora de faixa etária equivalente. Participaram da pesquisa 60 homens (30 jogadores de RPG e 30 não jogadores), com idades entre 18 e 25 anos. Foi aplicado o Inventário de Habilidades Sociais (Del Prette \& Del Prette, 2001) em ambos os grupos e um questionário nos jogadores. $\mathrm{Na}$ análise dos resultados do IHS dos dois grupos, o Qui Quadrado não se mostrou significativo ao nível de 5\%, ou seja, não se pode afirmar que os grupos apresentavam diferenças significativas nos fatores analisados, exceto no Fator 2 (habilidades de auto-afirmação na expressão de sentimento positivo) no grupo de jogadores, cujo valor foi consideravelmente menor que os demais. As entrevistas não indicaram diferença entre o convívio dos jogadores com colegas jogadores e não-jogadores e não houve correlação entre o tipo de sistema jogado e o nível de repertório social avaliado pelo IHS-Del-Prette nos jogadores. Pode-se verificar que, ainda que os meios de comunicação em massa especulem a respeito de conseqüências prejudiciais geradas pelo jogo de RPG, os resultados desta pesquisa não indicaram qualquer diferença entre os repertórios de habilidades sociais dos dois grupos.
\end{abstract}

Palavras-chave: Role playing game (RPG); Habilidades sociais; Jovens. 


\begin{abstract}
Role playing game (RPG) is a game based on verbal interaction, whose number of players have been increasing considerably, despite being accused of stimulating anti-social behavior. There is no scientific confirmation of such claim, but there is indication that players might present social skills deficits. The purpose of this research was to verify if the players' social skills differed from similar aged non-players social skills. The participants were 60 men (30 players and 30 non-players) ages ranging between 18 and 25 years old. The Inventário de Habilidades Sociais (Del Prette E Del Prette, 2001) was applied in both groups and an additional questionnaire was answered only by the players group. Comparing the scores of both groups obtained by the inventory application, the chi-square was not significant at 5\% level, i.e., it cannot be assured that there are significant differences concerning analyzed inventory factors, except for Factor 2 (self-assurance on positive sentiment expression skills) on players group, whose score was considerably smaller than the other factors' score. The interviews did not point out any difference between the players relationship with non-players and there was no correlation between the type of system played and the social repertoire level evaluated by means of the inventory. It was verified that, even if means of communication speculate about harmful consequences caused by RPG, the results of this research did not indicate any differences between the social skills repertoire of both groups.
\end{abstract}

Keywords: Role playing game (RPG); Social skills; Young people.

\section{INTRODUÇÃO}

O RGP, sigla para Role Playing Game (“jogo de representação”), foi criado em 1973 nos EUA por Dave Arneson. A representação das ações dentro do RPG ocorre, basicamente, por meio da fala e da imaginação de seus jogadores durante as sessões, que podem durar em média de duas a dez horas. O início de uma sessão se dá pela continuação da aventura a partir da interrupção feita ao final da sessão anterior (Hughes, 1988; Jackson, 1994; Cale, 2002).

$\mathrm{Na}$ maneira mais original e tradicional de RPG, os jogadores apenas descrevem situações, comportando-se verbalmente, não havendo representação corporal das ações de seus personagens (Cardwell, 1994). Apesar de haver diferentes formas de jogar RPG (diferentes sistemas), todas elas apresentam alguns elementos em comum: um grupo de pessoas, geralmente de três a sete jogadores, após escolherem um determinado sistema de jogo, definem a personalidade, ideologia, habilidades e inabilidades de seus personagens, quantificados por meio de atribuições (valores) numéricos em tabelas próprias. Um dos integrantes do grupo, designado "Mestre do jogo" (geralmente o jogador mais experiente do grupo), é responsável por criar previamente um esboço da futura aventura desenvolvida por todos durante as sessões (Hughes, 1988; Jackson, 1994).

O impacto das ações dos personagens é expresso pelo mestre, que apresenta um modelo matemático determinado (dependendo do sistema de RPG utilizado), estipulando uma jogada de diferentes tipos de dados característicos a este tipo de jogo (com quatro, seis, oito, dez e/ou vinte faces). Em virtude dessa variabilidade nas regras existentes entre os sistemas de RPG, foi criado nos EUA, ao final dos anos 1980, por Steve Jackson, um método universal de regras e bases para todos os tipos de RPG, denominado GURPS (Generic Universal Role Playing System "sistema de representação universal genérico"), introduzido no Brasil em meados de 1990, em virtude de sua versatilidade (Jackson, 1994). Atualmente, os sistemas GURPS e Dungeons \& Dragons são os mais difundidos no mundo.

Hughes (1988) aponta que mesmo havendo vários sistemas que possam ser utilizados em um jogo de RPG, o que compõe seu principal ponto característico e que talvez mais tenha contribuído para o aumento de sua popularidade (em universidades principalmente), é o fato de a ação 
do jogo ser gerada basicamente pelo processo de imaginação dos jogadores, sendo os demais recursos possivelmente utilizados (efeitos sonoros, maquiagem, figuras, fotos, etc.) meramente secundários à essência de sua estrutura, cujo objetivo é "uma forma de lazer que dá aos participantes a possibilidade de criarem histórias, de forma integral ou parcial, e viver em papéis dentro das mesmas" (Jackson, 1994, p. 8).

Entretanto, a popularidade do RPG nem sempre esteve atrelada ao interesse das pessoas pelo jogo propriamente dito, existindo, também, segundo Pavão (2000), alguns alertas sobre o perigo do jogo transformar-se em um meio de escapismo da realidade, justamente por criar universos ficcionais onde os jogadores projetariam algumas dificuldades em vez de lidar com elas no plano real. Essa hipótese tem se propagado rapidamente pela sociedade mediante os meios de comunicação, especialmente em países como os Estados Unidos e Canadá, que possuem maior número de jogadores ativos. Em 1994, estimava-se que existiam por volta de 7,5 milhões de jogadores ativos, ou seja, que jogavam pelo menos uma vez ao mês, em todo o mundo (Cardwell, 1994).

Apesar de haver um rápido crescimento do número de jogadores e também das especulações a respeito das influências do jogo, não há número significativo de dados empíricos que acompanhem esse processo. Derenard e Kline (1990) realizaram uma pesquisa com um total de 70 participantes, sendo 35 jogadores do jogo Dungeons \& Dragons (30 homens e cinco mulheres), com idade média de 21.2 anos, e 35 não-jogadores (25 homens e 10 mulheres), com idade média de 20.3 anos. Os participantes responderam um questionário (aplicado em grupo), contendo uma Escala de Anomia, que faz uma mensuração de alienação em geral, e uma Escala de Alienação, que mede seis diferentes tipos de alienação: sentimentos de impotência (powerlessness), de anormalidade (normlessness), de falta de propósito (meaninglessness), de estranhamento cultural (cultural estrangement), de estranhamento social (social estrangement) e de estranhamento no trabalho (estrangement from work). Os resultados não demonstraram níveis maiores de depressão, suicídio e sentimentos de falta de perspectiva nos jogadores, em comparação ao grupo-controle. Porém, o nível de alienação e de estranhamento cultural nos jogadores de RPG mostraram-se mais altos em comparação aos não jogadores, e ainda mais altos nos jogadores considerados mais envolvidos com o jogo, ou seja, que gastavam mais dinheiro na compra dos materiais necessários às sessões de RPG. Logo, podem-se observar dados relevantes na diferença encontrada no nível de alienação e de estranhamento cultural dos jogadores de RPG em comparação aos não-jogadores, além de um indicativo de aumento desses níveis de alienação em jogadores considerados mais envolvidos com a prática de RPG. Apesar da ausência de dados que de fato sustentem a hipótese de que o RPG aumenta os índices de comportamentos antisociais, o estudo de Derenard e Kline sugere que os níveis de alienação encontrados nos jogadores apontam para uma diferença concreta em sentimentos vinculados a comportamentos sociais. Tais sentimentos podem indicar desajuste por parte desses jogadores no que diz respeito à leitura que fazem do ambiente em que vivem e/ ou falta de habilidade para lidar com suas demandas, inclusive com as demandas sociais.

O desempenho dos indivíduos no meio social tem se mostrado um assunto de grande importância no meio acadêmico. Del Prette e Del Prette (1999) afirmam que grande parte das teorias do desenvolvimento aborda questões a esse respeito, destacando-se a importância das interações e relações sociais do homem durante seu ciclo vital como fatores de saúde mental. Para entender melhor como se dão essas interações, é necessário contextualizar a forma como isso ocorre no homem. Cada ser humano nasce com um equipamento biológico, cujo potencial de desenvolvimento depende de diversos fatores, externos e internos. $\mathrm{O}$ ambiente impõe uma série de demandas, às quais o indivíduo deve corresponder desenvolvendo constantemente novas habilidades (Del Prette \& Del Prette, 1999). Sendo este ambiente em sua maior parte social, destacam-se as habilidades sociais, cujo conceito "aplica-se à noção de existência de diferentes classes de comportamentos sociais no repertório do indivíduo para lidar com as demandas das situações interpessoais [...] $\mathrm{Na}$ dinâmica das interações, as habilidades sociais fazem parte dos componentes de um desempenho social bemsucedido" (Del Prette \& Del Prette, 2003, p. 31).

Caballo (1996) afirma ser impossível desenvolver uma definição consistente de habilidades sociais, em vista de elas serem parcialmente 
dependentes do contexto em que ocorrem, e de fatores como idade, sexo e nível sociocultural. Pode-se, no entanto, apontar quais as áreas mais recorrentes nas avaliações de habilidades sociais: iniciar e manter conversações, falar em público, expressar amor, agrado e afeto, defender os próprios direitos, pedir favores, recusar pedidos, fazer obrigações, aceitar elogios, expressar opiniões pessoais (inclusive discordantes), expressar justificadamente incômodo, desagrado ou enfado, e desculpar-se ou admitir ignorância (Caballo, 1996). Del Prette e Del Prette (2001) classificam-nas em habilidades sociais de comunicação, civilidade, assertivas, de direito e cidadania, empáticas, de trabalho e de expressão de sentimento positivo. Uma classificação ainda mais abrangente que pode ser acrescentada é o agrupamento das áreas citadas em componentes comportamentais (verbais de conteúdo, de forma e não-verbais), cognitivoafetivos (conhecimentos prévios, expectativas e crenças, e estratégia e habilidades de processamento), fisiológicos (taxa cardíaca, respostas eletromiográficas, respiração, resposta galvânica da pele, e fluxo sangüíneo) e ainda outros componentes (atividade física, aparência pessoal). Del Prette e Del Prette (1999) ainda sugerem que há evidências de que o repertório de habilidades sociais torna-se progressivamente mais elaborado no decorrer da infância, período no qual os pais (cuidadores em geral) modelam os comportamentos sociais de seus filhos ao reagirem diferentemente às manifestações de suas habilidades e também ao fornecerem instruções específicas para isso.

Nesse contexto, as dificuldades interpessoais podem ser compreendidas também como problemas que ocorrem no desenvolvimento de repertórios sociais. Dentre as hipóteses explicativas para essas dificuldades, Del Prette e Del Prette (2002) destacam os déficits no repertório, em que o comportamento social incompetente se daria pela falta de comportamentos verbais e não-verbais necessários a uma boa relação com o ambiente. Em se tratando das evidências já citadas a respeito de sentimentos de alienação, identificados em jogadores de RPG, pode-se apontar para a possibilidade de o comportamento desses indivíduos (jogar RPG com relativa freqüência) evidenciar a necessidade de afastar situações aversivas do contato com o ambiente social por meio da prática do RPG, principalmente em momentos de lazer. Tal comportamento seria caracterizado como uma esquiva social, na qual os jogadores evitariam circunstâncias potencialmente aversivas antes mesmo que elas ocorressem (Catania, 1999).

Com base nessas informações, pode-se levantar a hipótese de que a relação que os jogadores de RPG estabelecem com o jogo seja um meio de esquiva das relações interpessoais no meio social comum, em virtude de déficits de habilidades sociais em seus repertórios comportamentais. A proposta desta pesquisa é iniciar a investigação dessa possibilidade, estudando uma amostra de jogadores de RPG e uma amostra equivalente de pessoas que nunca tiveram contato com o jogo. $\mathrm{O}$ objetivo deste trabalho é investigar se as habilidades sociais dos jogadores de RPG diferem das habilidades sociais da população não-jogadora de faixa etária equivalente.

\section{MÉTODOS}

\section{Participantes}

Participaram da pesquisa 60 homens com idades entre 18 e 25 anos. Destes, 30 eram jogadores de RPG e 30 eram não-jogadores. As características da população jogadora abordada definiram as características da população não-jogadora.

\section{Local}

A pesquisa foi realizada em diferentes locais na cidade de Curitiba.

\section{Instrumentos}

Foi aplicado nos dois grupos o Inventário de Habilidades Sociais (IHS-Del-Prette \& Del Prette, 2001), que avalia cinco fatores relacionados às habilidades sociais: enfrentamento e autoafirmação com risco, auto-afirmação na expressão de sentimento positivo, conversação e desenvoltura social, auto-exposição a desconhecidos e situações novas e autocontrole da agressividade. O escore obtido pelos respondentes é classificado de acordo com a seguinte escala: repertório "bastante elaborado", "bom, acima da média", "médio", "bom, abaixo da média" e "com déficit".

Além do inventário, o grupo de jogadores respondeu a um questionário, que continha seis 
perguntas abertas e seis perguntas fechadas, perfazendo um total de 12 perguntas que se referiam às relações sociais do entrevistado com jogadores e não-jogadores, relações familiares e perfil socioeconômico.

\section{Procedimentos}

Foram adotados procedimentos distintos com cada grupo (jogadores e não-jogadores) para a coleta de dados, descritos a seguir.

\section{a) Grupo de Jogadores de RPG:}

As pesquisadoras se apresentaram como estudantes de Psicologia do Unicenp em listas virtuais de discussão sobre RPG, em uma livraria especializada em produtos para o jogo e em uma lan house. Os responsáveis pelos estabelecimentos foram contatados e, após apresentarem-se e descreverem a proposta de estudo, as pesquisadoras pediram autorização para abordar os jogadores de RPG que freqüentassem os locais selecionados. As autorizações foram registradas em uma carta de consentimento. Nos estabelecimentos e nas listas virtuais de discussão, foram convidados jogadores com idades entre 18 e 25 anos e que jogassem pelo menos uma vez ao mês, a participarem de uma pesquisa sobre hábitos sociais de jogadores de RPG. Os jogadores das listas de discussão que demonstraram interesse em participar da pesquisa foram convidados a comparecer à clínica de Psicologia da Universidade, em data e horário viáveis para esclarecimentos sobre a pesquisa, assinatura da carta de consentimento, aplicação do IHS e da entrevista. No caso dos jogadores abordados na livraria e lan house, a aplicação do inventário e da entrevista foi feita em uma sala do próprio local, disponibilizada pelos proprietários. Foi entregue aos participantes um endereço de e-mail e um telefone para contato com as pesquisadoras, por meio dos quais as possíveis dúvidas quanto à pesquisa pudessem ser esclarecidas. Também foi solicitado a cada participante que indicasse colegas jogadores de RPG, com idades entre $18 \mathrm{e}$ 25 anos, para participar da pesquisa. Tal procedimento caracteriza a técnica de snowball, que permitiu a captação de novos participantes a partir daqueles já entrevistados. A grande maioria dos jogadores foi selecionada por meio da abordagem na lan house e pela aplicação da técnica de snowball.

\section{b) Grupo de Não-jogadores:}

O grupo de não-jogadores foi composto a partir das características básicas da amostra de jogadores: idade, escolaridade e natureza das instituições de ensino freqüentadas (pública ou privada). A seleção de participantes deste grupo foi realizada pela abordagem direta de alguns estudantes nas instituições que freqüentavam e pela técnica de snowball, com base nos perfis preestabelecidos. Ao entrar em contato com tais pessoas, as pesquisadoras identificavam-se, apresentavam a proposta de pesquisa (sobre hábitos sociais dos jogadores de RPG) e perguntavam se o entrevistado conhecia o jogo. Aqueles que aceitaram participar da pesquisa e que afirmaram não conhecer ou nunca terem jogado assinaram a carta de apresentação e consentimento informado e, em seguida, responderam ao Inventário de Habilidades Sociais (IHS) em local adequado. Os resultados gerais e individuais foram enviados via e-mail a cada participante, tanto para jogadores quanto para não-jogadores.

\section{ANÁLISE DE DADOS}

A comparação entre os escores obtidos por meio da aplicação do IHS-Del-Prette em cada grupo foi feita a partir da aplicação do teste de hipótese ou Qui Quadrado. A análise das entrevistas semi-estruturadas foi feita pela comparação dos percentuais de respostas às perguntas.

\section{RESULTADOS}

Inicialmente, será feita uma breve apresentação das características das duas amostras estudadas. Em seguida, serão apresentados os dados referentes à aplicação do IHS em ambos os grupos (escore total e a comparação dos escores de cada fator avaliado). Finalmente, serão apresentados os dados das entrevistas realizadas com a amostra de jogadores de RPG.

A amostra de participantes foi caracterizada, predominantemente, por estudantes $(70 \%)$, dos quais 
$56,7 \%$ cursavam nível superior no período noturno (42,9\%), em instituição de ensino pública (52,4\%) ou particular $(47,6 \%)$. A grande maioria dos participantes trabalhava (70\%), sendo que 38,1\% em período vespertino e $23,9 \%$ em período integral. A renda familiar da maior parte dos participantes estava entre 8-20 salários mínimos (56,7\%).

Para avaliar há quanto tempo os jogadores mantinham o hábito de jogar RPG, foram estabelecidos os seguintes períodos: menos de 1 ano, entre 1 e 3 anos, entre 3 e 6 anos e mais de 6 anos. Grande parte da população jogadora afirmou jogar há mais de seis anos (66,7\% da amostra) ou entre 3 e 6 anos $(20 \%)$. A maioria dos jogadores $(63,3 \%)$ afirmou jogar RPG entre uma e quatro vezes por mês, e sempre com as mesmas pessoas $(77,7 \%)$. Quanto à opinião de seus familiares sobre o hábito de jogar RPG, $40 \%$ dos jogadores afirmaram que estes aprovavam com ressalvas, $23,3 \%$ afirmaram que suas famílias eram indiferentes, $10 \%$ disseram que seus familiares aprovavam e 10\% afirmaram que a família reprovava o hábito.

A Figura 1 apresenta a comparação entre os escores totais obtidos pelos grupos de jogadores e não-jogadores no IHS.

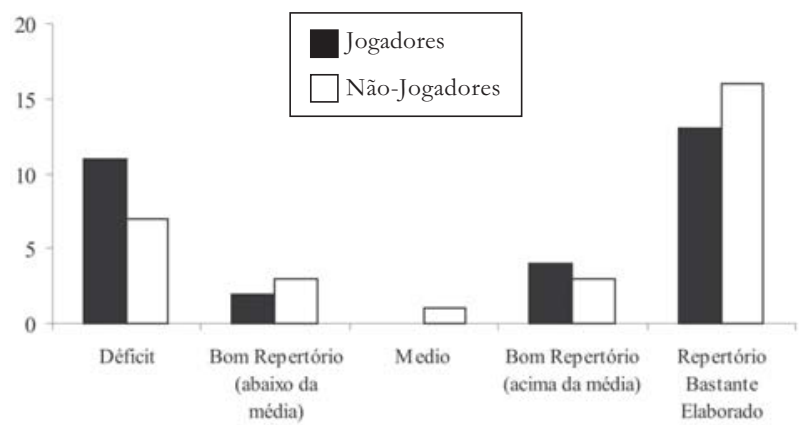

FIGURA 1 - Comparação do escore total obtido no IHS-Del Prette (2001) entre os grupos de jogadores e não-jogadores

De modo geral, analisando o escore total das duas amostras, observa-se uma distribuição muito parecida dos dois grupos estudados na escala de avaliação, ou seja, a maioria dos participantes das duas amostras apresentou um repertório bastante elaborado de habilidades sociais. Apareceram algumas diferenças discretas entre os grupos, porém nenhuma delas significativa.
A Figura 2 apresenta a comparação entre os escores obtidos pelos dois grupos nos fatores avaliados pelo inventário.

\section{Enfrentamento e auto-afirmação com risco (F1)}

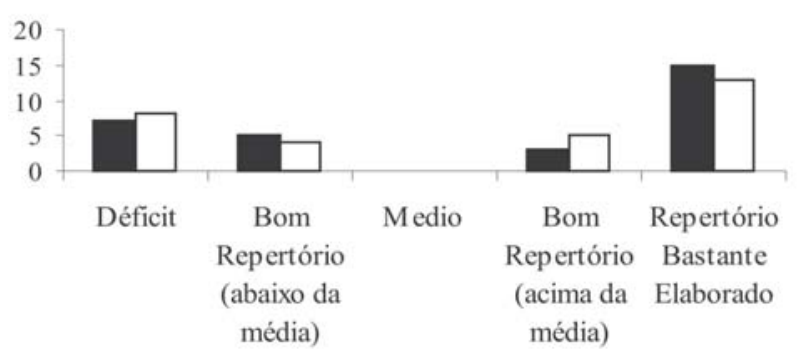

Auto-afirmação na expressão de
sentimentos positivos (F2)

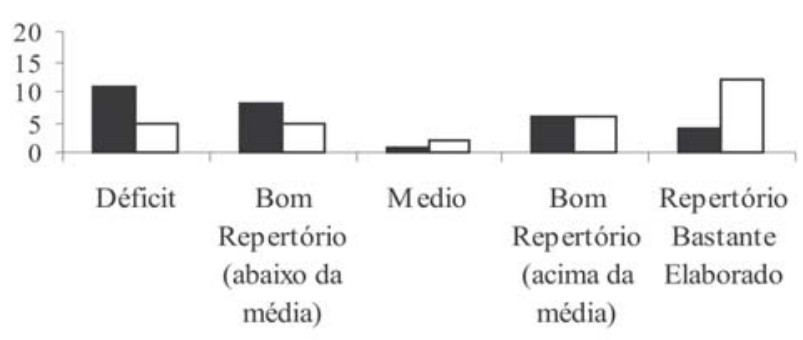

Conversação e desenvoltura social

(F3)

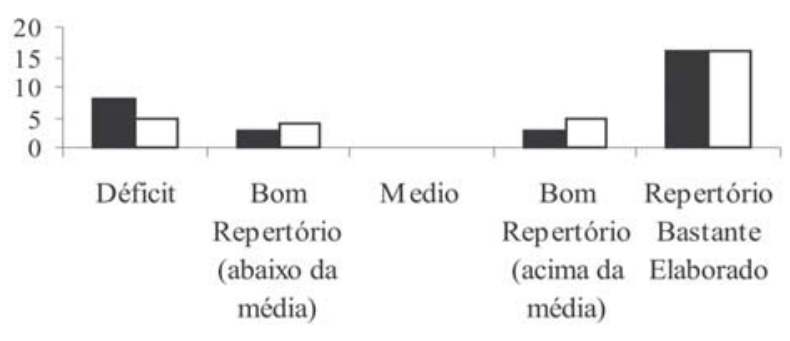

\section{Auto-exposição a desconhecidos e} situações novas (F4)

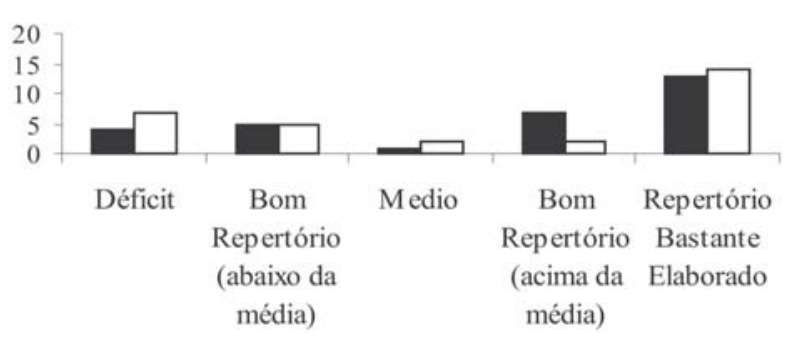


Autocontrole da agressividade (F5)

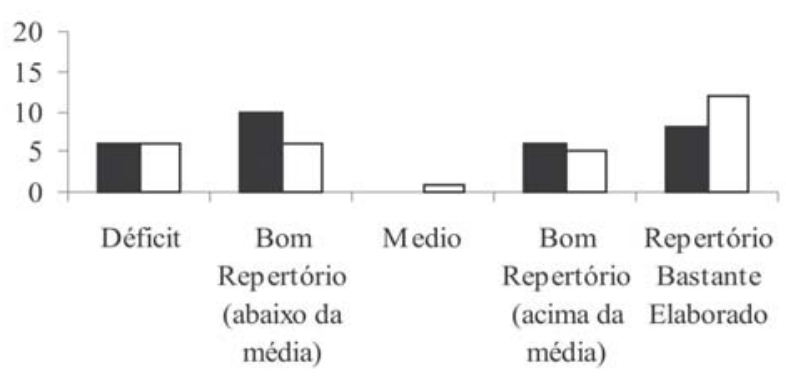

FIGURA 2 - Comparação entre escores de jogadores e não-jogadores nos Fatores 1, 2, 3, 4 e 5 do IHS-Del Prette (2001)

Pode-se observar uma polarização nos extremos da escala em praticamente todos os fatores, isto é, os escores médios foram obtidos por um número menor de participantes de ambos os grupos. Na comparação dos resultados dos dois grupos, o teste de hipótese ou Qui Quadrado não se mostrou significativo a $5 \%$, ou seja, com este estudo, não se pode afirmar que os grupos apresentam diferenças significativas quanto aos fatores estudados, conforme pode ser observado na Tabela 1 . Os valores de $p$ referentes aos escores total e dos fatores 1, 3, 4 e 5 são significativamente maiores que o valor de significância estabelecido $(p=0,05)$, no entanto, observa-se que o valor de $p$ referente ao Fator $2(p=0,0716)$ foi o que mais se aproximou do valor de significância $(p=0,05)$, sendo consideravel-mente menor que os demais valores. Observa-se que, de fato, pela amostra estudada, não é possível verificar se há diferenças significativas entre os grupos no que se refere ao escore do Fator 2 (já que o valor de $p$ é maior que 0,05), mas há evidências de diferenças consideráveis entre tal fator e os demais, o que permite questionar a validade desse dado em uma amostra com um maior número de participantes. Em outras palavras, não se pode afirmar com certeza se realmente os jogadores de RPG não apresentam diferenças em suas habilidades de auto-afirmação na expressão de sentimento positivo ou se, de fato, podem apresentar repertório diferenciado na área analisada.

TABELA 1 - Resultado do teste do qui quadrado* para associação entre ser jogador de RPG e repertório social**

\begin{tabular}{lc}
\hline ÁREAS AVALIADAS & VALORDE $\boldsymbol{p}^{*}$ \\
\hline Escore total & 0,70571 \\
$\begin{array}{l}\text { Enfrentamento e auto-afirmação } \\
\text { com risco (F1) }\end{array}$ & 0,84452 \\
$\begin{array}{l}\text { Auto-afirmação na expressão } \\
\text { de sentimento positivo (F2) }\end{array}$ & 0,07161 \\
$\begin{array}{l}\text { Conversação de desenvoltura } \\
\text { social (F3) }\end{array}$ & 0,72080 \\
$\begin{array}{l}\text { Auto-exposição a desconhecidos } \\
\text { e situações novas (F4) }\end{array}$ & 0,53420 \\
Autocontrole da agressividade (F5) & 0,61493 \\
\hline
\end{tabular}

* nível de significância de 0,05.

** avaliado pelo IHS-Del-Prette (2001).

O questionário aplicado nos jogadores teve por objetivo investigar os comportamentos avaliados no IHS, verificando se os jogadores relatavam diferenças em seus comportamentos quando se relacionavam com pares que jogavam RPG e pares que não jogavam RPG. Foram descritas no questionário situações sociais cotidianas, perguntando o grau de conforto dos jogadores na relação entre pares jogadores e nãojogadores em determinadas situações. As situações avaliadas envolveram os seguintes comportamentos: conversar, cobrar, elogiar, falar em público, encerrar conversas, receber críticas, ser contrariado e fazer correções. A Figura 3 apresenta a freqüência com que os participantes relataram se sentir confortáveis ou não nas diferentes situações propostas. 


\section{Falar em público}

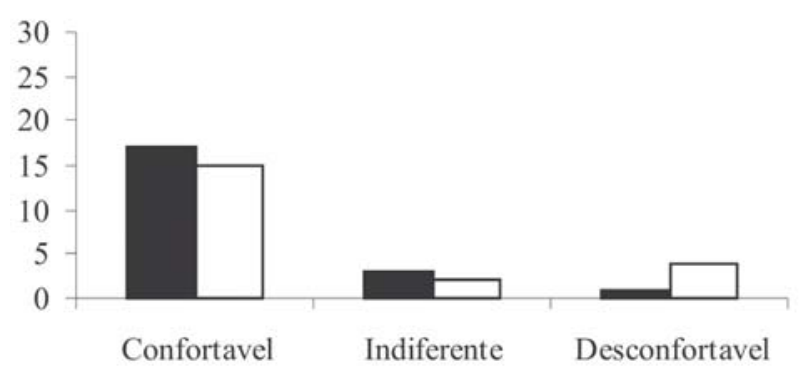

Conversar

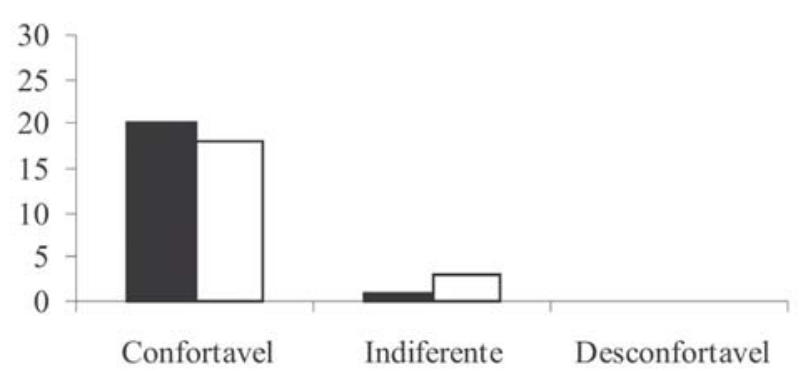

Cobrar

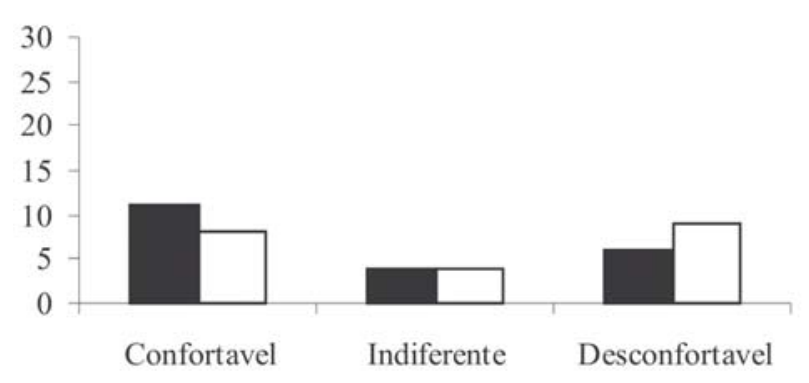

\section{Encerrar conversa}

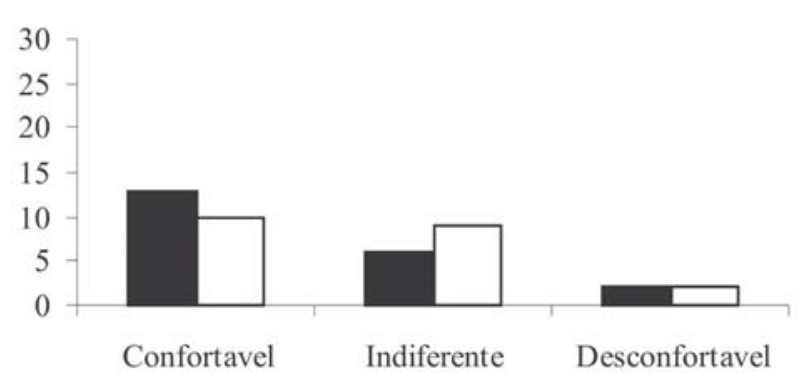

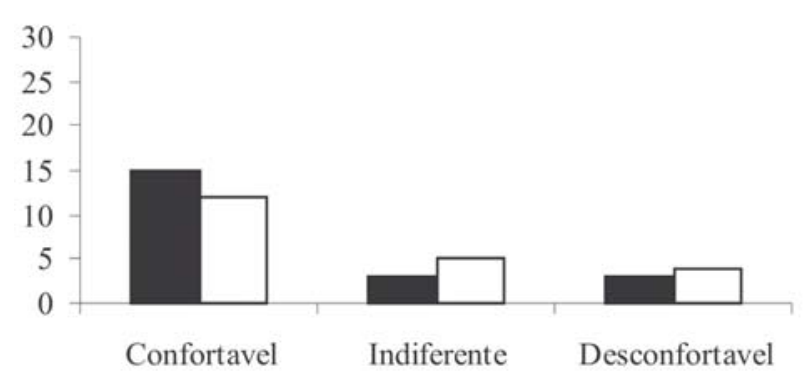

Elogiar

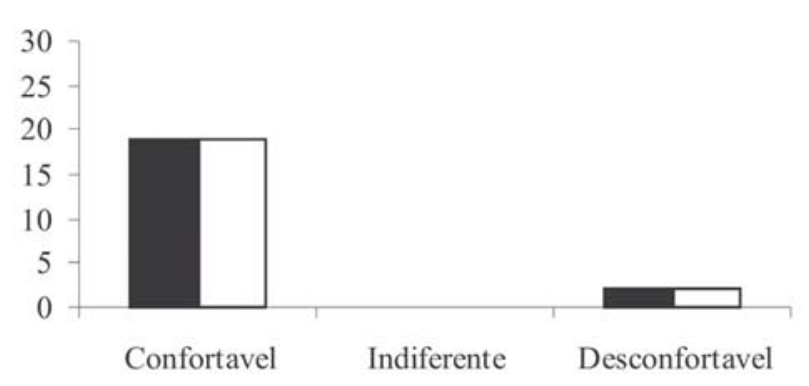

FIGURA 3 - Grau de conforto relatado pelos jogadores na relação com colegas jogadores e não-jogadores

Ao analisar as respostas assinaladas pelos participantes nas situações propostas, não é possível verificar qualquer diferença no grau de conforto relatado por eles em relação ao seu convívio com colegas jogadores e não-jogadores. De modo geral, a maioria dos jogadores declarou se sentir confortável nas suas relações tanto com colegas jogadores quanto com colegas não jogadores. Além disso, não houve correlação entre o tipo de sistema jogado pelos participantes e o nível de repertório social avaliado pelo IHS.

\section{CONSIDERAÇÕES FINAIS}

Durante os últimos quinze anos, o jogo de RPG tem sido fortemente criticado por representantes da sociedade, como grupos religiosos e pais de jogadores, que sustentam vários grupos anti-RPG (ex. B.A.D.D. - Bothered About Dungeons and Dragons e C.C.I.N. - Cult Crime Impact Network), além de livros, artigos de revistas e documentários, afirmando que esse tipo de jogo induz comportamentos prejudiciais 
nos jogadores, como cultos satânicos, prática de bruxaria, suicídio, estupro, assassinato, entre outros. Em muitos casos de tribunais que apontaram o RPG como principal fator responsável em atos criminais, alegou-se que os jogadores criminosos estariam muito envolvidos em uma realidade paralela em função de seus personagens (Cale, 2002). Tais especulações levaram à elaboração de alguns estudos sobre a relação de comportamentos anti-sociais com o jogo. Segundo Cale (2002), após longos estudos realizados pelos membros da American Association of Suicidology e Center for Disease Control nos EUA e Health \& Welfare no Canadá, não foram encontradas quaisquer ligações entre o jogo Dangeons \& Dragons e adolescentes suicidas.

O estudo realizado por Derenard e Kline (1990), com 70 participantes (35 jogadores e 35 nãojogadores), não indicou níveis maiores de depressão, suicídio e sentimentos de falta de perspectiva nos jogadores, em comparação ao grupo-controle. No entanto, os níveis de alienação e de estranhamento cultural nos jogadores de RPG mostraram-se mais altos em comparação aos não-jogadores, e ainda mais altos nos jogadores considerados mais envolvidos com o jogo. Os dados apresentados na presente pesquisa, mesmo não sendo conclusivos, apontam para aspectos mais específicos do comportamento social dos jogadores, não estando diretamente relacionados a comportamentos agressivos constantemente ressaltados pelos meios de comunicação. Considerando as evidências apresentadas em algumas pesquisas de que havia diferenças significativas na maneira como jogadores lidavam com as demandas do ambiente, levantou-se a hipótese de que a relação que os jogadores de RPG estabelecem com o jogo seria um meio de esquiva das relações interpessoais no meio social comum, em virtude de possíveis déficits de habilidades sociais em seus repertórios comportamentais. A literatura apresenta informações que dão suporte a tal hipótese, ressaltando que grande parte da popularidade do jogo é sustentada por alguns alertas sobre o perigo deste se transformar em um meio de escapismo da realidade, por criar universos ficcionais onde os jogadores projetariam algumas dificuldades em vez de lidar com elas no plano real (Pavão, 2000).

Levando-se em consideração que o presente estudo representa uma pesquisa exploratória, com o objetivo de levantar dados pouco disponíveis no meio científico, foram estruturados grupos equivalentes de jogadores e não-jogadores para que a comparação entre suas habilidades sociais pudesse ser feita. Nos dados apresentados, não foram observadas diferenças significativas entre tais grupos, tanto com relação ao escore geral de habilidades sociais quanto aos fatores específicos. Entretanto, observou-se que o valor de $p$ do Fator 2 (auto-afirmação na expressão de sentimentos positivos) foi o que mais se aproximou do valor de significância estabelecido, indicando evidências de que pode haver diferenças consideráveis entre tal fator e os demais. Tal fato permite questionar se o valor de $p$ referente ao Fator 2 ainda estaria acima do valor de significância se fosse calculado em uma amostra com maior número de participantes, já que a amostra selecionada é relativamente pequena (30 homens em cada grupo). Se, de fato, há uma diferença significativa no que se refere às habilidades de "auto-afirmação na expressão de sentimento positivo" entre os grupos de jogadores e não-jogadores em amostras com maior número de participantes, é necessário que este dado seja levantado. Também podem ser levantadas questões sobre a relação entre a preferência de diferentes sistemas de jogo de RPG com déficits de habilidades sociais ou com outros fatores relacionados à personalidade dos jogadores.

Se, por um lado, os meios de comunicação em massa têm especulado a respeito de conseqüências prejudiciais geradas pelo jogo de RPG, por outro, os resultados da presente pesquisa não indicaram haver qualquer diferença entre os repertórios de habilidades sociais dos dois grupos de participantes. A hipótese inicialmente levantada foi refutada com a análise dos níveis de significância obtidos entre os grupos.

Apesar de os dados do presente estudo não apontarem para níveis diferenciados de habilidades sociais entre a população de jogadores e a população em geral, ao acrescentá-los aos dados coletados na pesquisa de Derenard e Kline (1990), por exemplo, pode-se afirmar que o jogo em si pode proporcionar condições para comportamentos de alienação, pela própria estrutura que o embasa, em que são criados universos predominantemente ficcionais entre um número determinado de pessoas. No entanto, os dados aqui apresentados apontam que jogar RPG não parece ser um fator que possa, individualmente, gerar condutas inadequadas na 
sociedade, e nem que é uma atividade procurada predominantemente por pessoas que apresentam déficits de relacionamento social. A importância deste estudo e de outros que eventualmente possam ser conduzidos sobre o tema reside na discussão sobre a importância de se identificar déficits habilidades sociais, seus fatores determinantes e suas conseqüências para a vida dos indivíduos. Autores como Del Prette e Del Prette (2002) apresentam preocupações com as possíveis conseqüências de déficits de habilidades sociais em etapas formativas da vida do sujeito, preocupações reforçadas pelas evidências de correlação entre tais déficits e diversos problemas psicológicos como delinqüência juvenil, desajustamento escolar, suicídio, problemas conjugais e síndromes clínicas, como depressão e esquizofrenia. Considerando que o RPG é um jogo predominantemente praticado por adolescentes e jovens adultos, seria importante verificar, em estudos mais amplos, se, de fato, tal população tende a buscar esse tipo de atividade em função de suas características e de que maneira esse jogo pode maximizar eventuais dificuldades interpessoais.

\section{REFERÊNCIAS}

Caballo, V. E. (1996). Manual de técnicas de terapia e modificação do comportamento. São Paulo: Santos.

Cale, C. The real truth about dungeons $\&$ dragons. Recuperado em 5 ago. 2006: http:/ /www.cale.com/paper.htm

Cardwell Jr, P. (1994). The attacks on role-playing games. Skeptical Inquirer, 18(2), 157-165, 1994. Recuperado em 6 ago. 2006, da Studies About Fantasy Role-Playing Games: http:// www.rpgstudies.net/cardwell/attacks.html

Catania, A. C. (1999). Aprendizagem: Comportamento, linguagem e cognição. Porto Alegre: Artmed.

Cozby, P. C. (2003). Métodos de pesquisa em ciências do comportamento. São Paulo: Atlas.

Del Prette, A. \& Del Prette, Z. A. P. (1999). Psicologia das habilidades sociais: Terapia e educação (3 ed.). Petrópolis: Vozes.
Del Prette, A., \& Del Prette, Z. A. P. (2001). Inventário de habilidades sociais (I. H. S. - Del Prette - Del Prette): Manual de aplicação, apuração e interpretação. São Paulo: Casa do Psicólogo.

Del Prette, A., Del Prette, Z. A. P. (1999). Habilidades sociais, desenvolvimento e aprendizagem: Questões conceituais, avaliação e intervenção. Campinas: Alínea, 2003.

Derenard, L. A. \& Kline, L. M. (1990). Alienation and the game dungeons and dragons. Psychological Reports, 66(3), 1219-1222.

Hughes, J. (1988). Therapy is fantasy: Roleplaying, healing and the construction of symbolic order. Recuperado em 6 ago. 2006, da Studies About Fantasy Role-Playing Games: http:// www.rpgstudies.net/hughes/ therapy_is_fantasy.html

Jackson, S. (1994). Módulo básico RPG GURPS (2a ed.). São Paulo: Devir.

Pavão, A. (2000). A aventura da leitura e da escrita entre mestres de roleplaying game (RPG) (2 ed.). Rio de Janeiro: Devir.

Recebido: 02/11/2007 Received: 11/02/2007

Aprovado: 03/03/2008 Approved: 03/03/2008 